\title{
Leukemic transformation driven by an ASXL1 mutation after a JAK2V617F-positive primary myelofibrosis: clonal evolution and hierarchy revealed by next-generation sequencing
}

\author{
Francisca Ferrer-Marín ${ }^{1 *}$, Beatriz Bellosillo², Luz Martínez-Avilés ${ }^{2}$, Gloria Soler ${ }^{1}$, Pablo Carbonell³ ${ }^{3}$ Ginés Luengo-Gil ${ }^{1}$,
} Eva Caparrós ${ }^{1}$, José M Torregrosa ${ }^{1}$, Carlos Besses $^{4}$ and Vicente Vicente ${ }^{1}$

\begin{abstract}
We have characterized the molecular changes underlying the transformation of a JAK2V617F+'myelofibrosis with trisomy 8, into a JAK2V617F-negative leukemia. Leukemic clone did not carry JAK2V617F mutation, but showed ASXL1 mutation (R693X). This mutation was identified in a low percentage at diagnosis by next-generation sequencing. Using this technology in serial specimens during the follow-up, we observed a progressive expansion of the ASXL1-mutated minor clone, whereas the JAK2V617F+'-clone carrying trisomy 8 decreased. Hematologic progression occurred simultaneously with an ASXL1-R693X-negative lung-cancer. This is the first report showing a clear association between the expansion of an ASXL1-mutated clone and the leukemic transformation of myelofibrosis.
\end{abstract}

Keywords: Myelofibrosis, ASXL1, Gene mutations, Acute myeloid leukemia, Clonality, Next-generation sequencing

\section{Letters to the editor}

It is known that patients with $J A K 2 V 617 F^{+}$myeloproliferative neoplasms (MPNs) can progress to a JAK2V617Facute myeloid leukemia (AML) [1-3]. These two phases of the disease may represent two different clones [1], however, the time-dependent clonal hierarchy is just beginning to be elucidated $[4,5]$.

ASXL1 is the second most frequently mutated gene after JAK2 ( 34.5\%) in myelofibrosis (MF) [6]. ASXL1 mutations are also found in solid neoplasms and all types of myeloid malignancies [7]. They are associated with aggressive disease [8] but their role in leukemic transformation remains controversial. ASXL1 mutations correlated with progression to blast-state in myelodysplastic syndromes and chronic myelomonocytic leukaemia $[9,10]$ while in MF, they are detectable in most patients at diagnosis [11], and they are present in chronic- and blast-phases [2] with

\footnotetext{
* Correspondence: fferrermarin@gmail.com

${ }^{1}$ Hematology and Medical Oncology Unit, Hospital Universitario MoralesMeseguer, Centro Regional de Hemodonación, C/Ronda de Garay, sn. 3003, Murcia, Spain

Full list of author information is available at the end of the article
}

the same prevalence [6]. These findings suggest that ASXL1 mutations play a crucial role in the pathogenesis of MF $[6,11]$ but they do not directly cause a leukemic phenotype $[2,6]$. We here characterize the molecular changes associated to the leukemic transformation of a patient with primary-MF (PMF) using next-generation sequencing (NGS). By the time of the hematologic progression, the patient also developed a lung adenocarcinoma. The relationship between the clonal hierarchy and phenotype disease over time are discussed.

\section{Case presentation}

A 62-year-old male with 126 pack-year smoking history, cardiomyopathy and chronic-pulmonary disease was referred to our Department in May' 2007 for evaluation of anemia, splenomegaly and fever. Following a peripheral blood (PB) and a bone marrow (BM) examination, a diagnosis of PMF according to WHO criteria was made, IPSS intermediate-2 [12]. Genetic analysis revealed a trisomy 8 in all 18 metaphases analyzed and the JAK2V617F mutation. With hydroxyurea, the patient achieved a complete resolution of fever and splenomegaly, and hemoglobin 
normalization. Thirty months later, he started with lumbar pain and leukocytosis $\left(12.9 \times 10^{9} / \mathrm{L}\right)$. A new BM biopsy showed severe fibrosis with osteosclerosis. Due to the patients's comorbidities, allogeneic transplant was not possible and hydroxyurea was continued. In December' 2010, the patient developed fever, splenomegaly, marked leukocytosis $\left(81.3 \times 10^{9} / \mathrm{L}\right)$ and required red-cell transfusions. A new BM biopsy confirmed leukemic transformation (Figure 1A) but fluorescence in situ hybridization (FISH) analysis discarded trisomy 8. Hydroxyurea was increased achieving a good control of leukocyte count. Few weeks later, he began with back and thoracic pain. A computed tomography (CT) scan revealed a speculated right lung nodule (Figure 1B). Biopsy confirmed non-small-cell lung cancer (NSCLC) (T1NOMX) and a PET-CT for staging was made (Figure $1 C$ ). Despite starting treatment for AML with thioguanine, the patient died because of acute congestive heart and liver failure. A post-mortem liver biopsy uncovered metastatic infiltration by NSCLC.

\section{Discussion}

To further investigate the molecular mechanisms underlying neoplastic progression in this case, we performed $J A K 2$ V617F allele burden in PB granulocytes obtained at three time points, by allele-specific qRT-PCR [13]. $J A K 2 V 617 F$ allele percentage decreased from $30 \%$ at diagnosis to undetectable level at blast-phase with an intermediate value of $20 \%$ (Figure 2A). A clonal analysis with microsatellites for 4 markers on chromosome $9 \mathrm{p}$ flanking $J A K 2$, on $\mathrm{PB}$ granulocytes taken at diagnosis
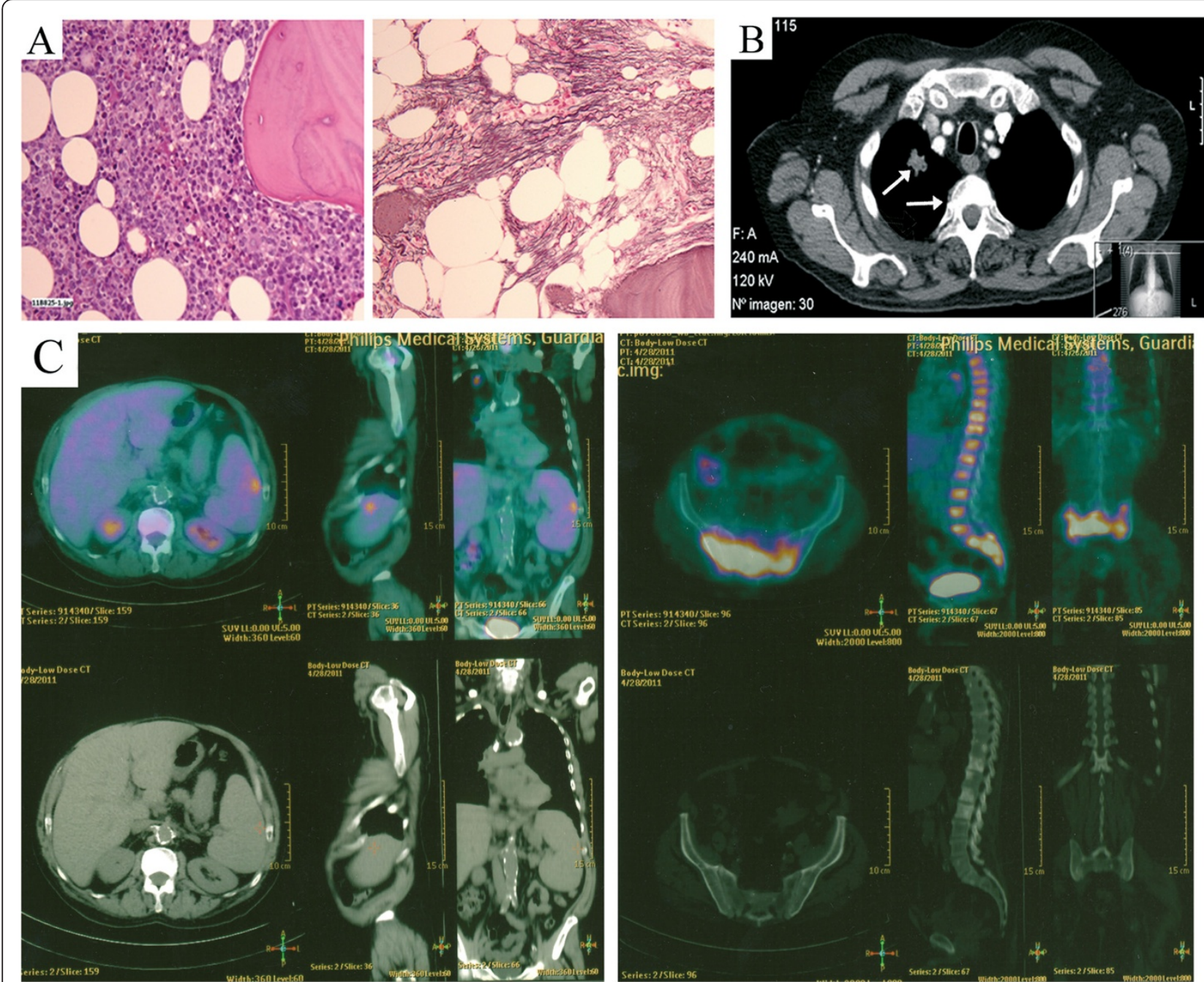

Figure 1 Histologic and radiologic studies at the time of leukemic transformation. (A) BM biopsy showing immature myeloid proliferation without segmentation (blasts $>20 \%$ ) and dysplastic megakaryocytes. With silver staining (right panel), marked reticulin fibrosis associated with osteoesclerosis was also shown. (B) Chest CT scan showing an increase in bone density of the vertebral bodies and a right lung nodule of $2 \times$ $2 \mathrm{~cm}$ in size with speculated edges. (C) Positron-emission tomography with CT showing a markedly increased of ${ }^{18}$ F-FDG uptake in the BM of the vertebral bodies; sacrum; extremity bones (specially left humerus); and focal in the spleen. 


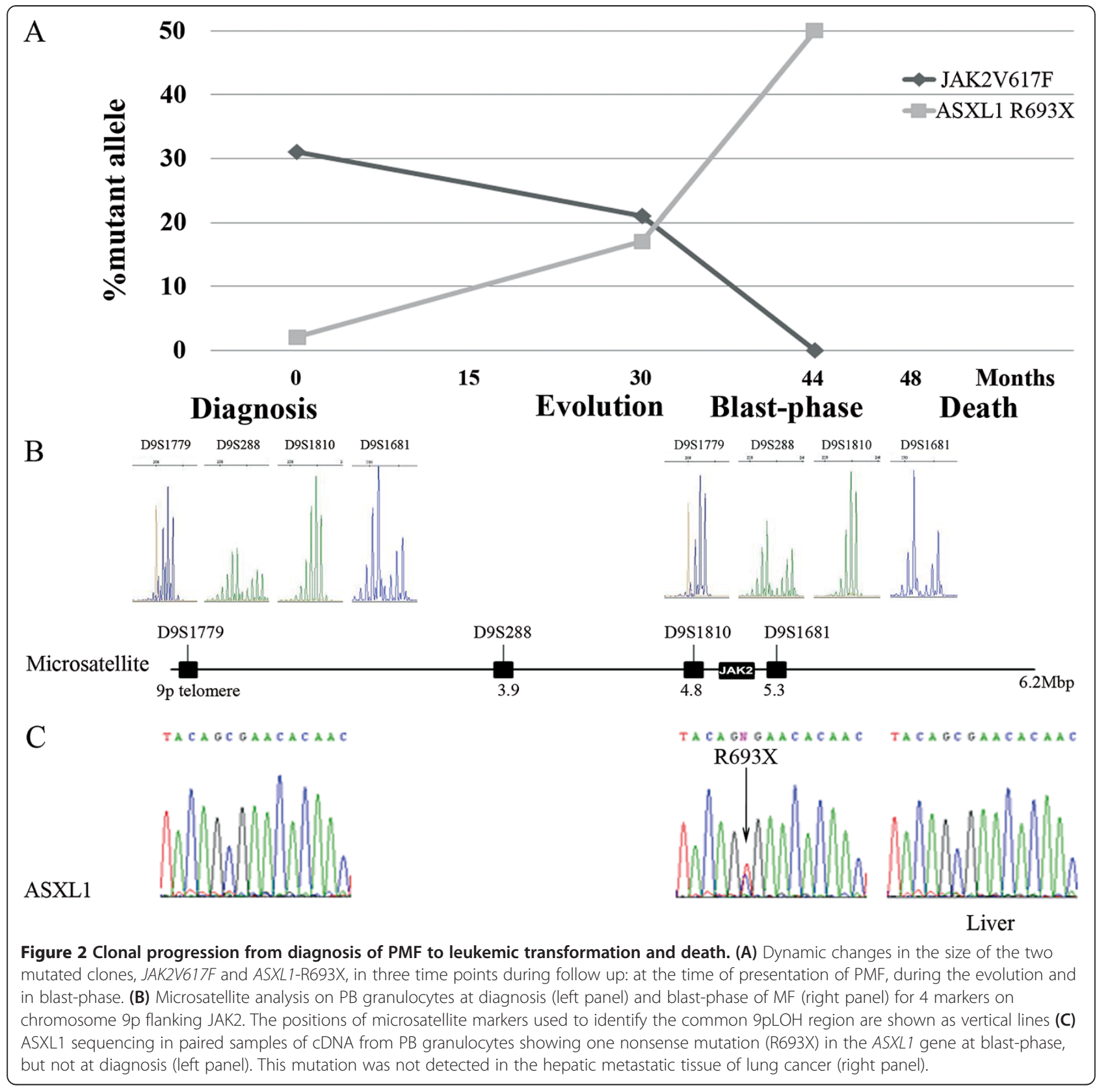

and in the blast-phase, [14] did not show loss of heterozygosity on chromosome 9p $(9 \mathrm{pLOH})$, either at diagnosis $\left(J A K 2 V 617 F^{+}\right.$-clone) or at blast-stage (dominant $J A K 2 V 617 F^{-}$-clone) (Figure $2 \mathrm{~B}$ ), suggesting that at presentation, two independent clones were likely present in our patient. To address this question, sequencing of ASXL1 (exon 12), TET2 (all exons), TP53 (exon 4-9), IDH1 (R132), IDH2 (R140, R172), c-CBL (exons 8-9) by Sanger and SRSF2 (exon 1), SF3B1 (exons 14-15) by NGS (454-GS Junior platform) were performed, in the same samples, as described [15,16]. At blast-phase, we identified an ASXL1-nonsense mutation (R693X), which was not present at diagnosis either by conventional sequencing (Figure $2 \mathrm{C}$ ) or by high resolution melting analysis (not shown). However, by using NGS (sensibility $1 \%,[17]$ ) we were able to detect the ASXL1-R693X mutation at diagnosis in a very low level (2\%). Additionally, using NGS at two time-points during follow-up, we observed an expansion of the ASXL1-R693X subclone, with a maximum value of $50 \%$ at blast-phase (Figure $2 \mathrm{~A}$ ).

Since ASXL1 has been involved in epithelial malignancy tumorigenesis [18] and cancer [7], we sequenced $A S X L 1$ gene in the hepatic metastatic tissue of lung cancer, but ASXL1-R693X mutation was not detected (Figure 2C), suggesting that at least three malignant clones might be present. 
Overall, in this patient, at early disease, the PMF phenotype was driven mainly by a JAK2V617F $F^{+}$-dominant clone carrying trisomy 8 . During the evolution this clone declined, whereas the ASXL1-mutated minor clone expanded, promoting the progression to leukemia. The reasons for these gradual shifts are unknown. Although hydroxyurea may induce a decrease in JAK2V617F allele burden in JAK2V617F $F^{+}$-MPNs $[13,19]$, leukemic transformation in MF can occur without any prior therapy [20]. Furthermore, ASXL1-R693X mutation, as other mutations affecting genes with epigenetic role, likely favor the occurrence of secondary genetic events and, in association with other cooperating mutations, promotes blast-crisis [5].

The molecular mechanisms undergoing the myeloid leukemogenesis promoted by $A S X L 1$ have been recently reported [21], but in MF, the role of ASXL1 mutations in leukemic transformation is still unclear $[2,6,22]$. By using NGS, we report, for the first time, an association between expansion of an ASXL1-mutated clone and MF progression to AML suggesting that in MF, as in other myeloid malignancies, ASXL1 mutations play a role in leukemic transformation. Given the prevalence of ASXL1 mutations in patients with MF, determination of ASXL1 mutation status in these patients could help in the molecular disease monitoring.

\section{Consent}

Written informed consent was obtained from the next of kin of the patient for publication of this Case report. A copy of the written consent is available for review by the Editor-in-Chief of this journal.

\section{Competing interests}

The authors declare that they have no competing interests.

\section{Authors' contributions}

FFM provided clinical information, directed the study and wrote the manuscript. BB designed experiments, analyzed the sequencing data and contributed to the manuscript. LMA performed the molecular biology studies. GS performed cytogenetic and FISH analysis. PC performed the microsatellite analysis. EC and GLG contributed to perform molecular analysis experiments. JMT carried out acquisition of data's patient. CB and W supervised the study and were responsible for manuscript review. All authors have reviewed and approved the manuscript.

\section{Acknowledgments}

We thank Dr J Corral for his helpful discussions.

\footnotetext{
Author details

${ }^{1}$ Hematology and Medical Oncology Unit, Hospital Universitario MoralesMeseguer, Centro Regional de Hemodonación, C/Ronda de Garay, sn. 3003, Murcia, Spain. ${ }^{2}$ Department of Pathology, Hospital del Mar-IMIM, Barcelona, Spain. ${ }^{3}$ Molecular Genetics Unit, Hospital Universitario Virgen de la Arrixaca, Murcia, Spain. ${ }^{4}$ Department of Hematology, Hospital del Mar-IMIM, Barcelona, Spain.
}

Received: 1 September 2013 Accepted: 3 September 2013

Published: 8 September 2013

\section{References}

1. Beer PA, Delhommeau F, LeCouedic JP, Dawson MA, Chen E, Bareford D, Kusec R, McMullin MF, Harrison CN, Vannucchi AM, et al: Two routes to leukemic transformation after a JAK2 mutation-positive myeloproliferative neoplasm. Blood 2010, 115:2891-2900.

2. Abdel-Wahab O, Manshouri T, Patel J, Harris K, Yao J, Hedvat C, Heguy A, Bueso-Ramos C, Kantarjian H, Levine RL, Verstovsek S: Genetic analysis of transforming events that convert chronic myeloproliferative neoplasms to leukemias. Cancer Res 2010, 70:447-452.

3. Theocharides A, Boissinot M, Girodon F, Garand R, Teo SS, Lippert E, Talmant P, Tichelli A, Hermouet S, Skoda RC: Leukemic blasts in transformed JAK2-V617Fpositive myeloproliferative disorders are frequently negative for the JAK2-V617F mutation. Blood 2007, 110:375-379.

4. Jager R, Kralovics R: Molecular basis and clonal evolution of myeloproliferative neoplasms. Haematologica 2010, 95:526-529.

5. Vainchenker W, Delhommeau F, Constantinescu SN, Bernard OA: New mutations and pathogenesis of myeloproliferative neoplasms. Blood 2011, 118:1723-1735.

6. Stein BL, Williams DM, O'Keefe C, Rogers O, Ingersoll RG, Spivak JL, Verma A, Maciejewski JP, McDevitt MA, Moliterno AR: Disruption of the ASXL1 gene is frequent in primary, post-essential thrombocytosis and postpolycythemia vera myelofibrosis, but not essential thrombocytosis or polycythemia vera: analysis of molecular genetics and clinical phenotypes. Haematologica 2011, 96:1462-1469.

7. Abdel-Wahab O, Dey A: The ASXL-BAP1 axis: new factors in myelopoiesis, cancer and epigenetics. Leukemia 2013, 27:10-15.

8. Gelsi-Boyer V, Brecqueville M, Devillier R, Murati A, Mozziconacci MJ, Birnbaum D: Mutations in ASXL1 are associated with poor prognosis across the spectrum of malignant myeloid diseases. J Hematol Oncol 2012, 5:12.

9. Thol F, Friesen I, Damm F, Yun H, Weissinger EM, Krauter J, Wagner $K$, Chaturvedi A, Sharma A, Wichmann M, et al: Prognostic significance of ASXL1 mutations in patients with myelodysplastic syndromes. $J$ Clin Oncol 2011, 29:2499-2506.

10. Gelsi-Boyer V, Trouplin V, Roquain J, Adelaide J, Carbuccia N, Esterni B, Finetti P, Murati A, Arnoulet C, Zerazhi H, et al: ASXL1 mutation is associated with poor prognosis and acute transformation in chronic myelomonocytic leukaemia. Br J Haematol 2010, 151:365-375.

11. Ricci C, Spinelli O, Salmoiraghi S, Finazzi G, Carobbio A, Rambaldi A: ASXL1 mutations in primary and secondary myelofibrosis. Br J Haematol 2012, 156:404-407.

12. Cervantes F, Dupriez B, Pereira A, Passamonti F, Reilly JT, Morra E, Vannucchi AM, Mesa RA, Demory JL, Barosi G, et al: New prognostic scoring system for primary myelofibrosis based on a study of the International Working Group for Myelofibrosis Research and Treatment. Blood 2009, 113:2895-2901.

13. Besses C, Alvarez-Larran A, Martinez-Aviles L, Mojal S, Longaron R, Salar A, Florensa L, Serrano S, Bellosillo B: Modulation of JAK2 V617F allele burden dynamics by hydroxycarbamide in polycythaemia vera and essential thrombocythaemia patients. Br J Haematol 2011, 152:413-419.

14. Kralovics R, Passamonti F, Buser AS, Teo SS, Tiedt R, Passweg JR, Tichelli A, Cazzola M, Skoda RC: A gain-of-function mutation of JAK2 in myeloproliferative disorders. N Engl J Med 2005, 352:1779-1790.

15. Martinez-Aviles L, Besses C, Alvarez-Larran A, Torres E, Serrano S, Bellosillo B: TET2, ASXL1, IDH1, IDH2, and c-CBL genes in JAK2- and MPL-negative myeloproliferative neoplasms. Ann Hematol 2012, 91:533-541.

16. Martinez-Aviles $L$, Alvarez-Larran A, Besses C, Navarro G, Torres $E$, Longaron R, Angona A, Pedro C, Florensa L, Serrano S, Bellosillo B: Clinical significance of clonality assessment in JAK2V617F-negative essential thrombocythemia. Ann Hematol 2012, 91:1555-1562.

17. Pietra D, Brisci A, Rumi E, Boggi S, Elena C, Pietrelli A, Bordoni R, Ferrari M, Passamonti F, De Bellis G, et al: Deep sequencing reveals double mutations in cis of MPL exon 10 in myeloproliferative neoplasms. Haematologica 2011, 96:607-611.

18. Scotto L, Narayan G, Nandula SV, Arias-Pulido H, Subramaniyam S, Schneider A, Kaufmann AM, Wright JD, Pothuri B, Mansukhani M, Murty W: Identification of copy number gain and overexpressed genes on chromosome arm 20q by an integrative genomic approach in cervical cancer: potential role in progression. Genes Chromosomes Cancer 2008, 47:755-765.

19. Girodon F, Schaeffer C, Cleyrat C, Mounier M, Lafont I, Santos FD, Duval A, Maynadie $M$, Hermouet S: Frequent reduction or absence of detection of the JAK2-mutated clone in JAK2V617F-positive patients within the first years of hydroxyurea therapy. Haematologica 2008, 93:1723-1727. 
20. Bjorkholm M, Derolf AR, Hultcrantz M, Kristinsson SY, Ekstrand C, Goldin LR, Andreasson B, Birgegard G, Linder O, Malm C, et al: Treatment-related risk factors for transformation to acute myeloid leukemia and myelodysplastic syndromes in myeloproliferative neoplasms. J Clin Oncol 2011, 29:2410-2415.

21. Abdel-Wahab O, Adli M, LaFave LM, Gao J, Hricik T, Shih AH, Pandey S, Patel JP, Chung YR, Koche R, et al: ASXL1 mutations promote myeloid transformation through loss of PRC2-mediated gene repression. Cancer Cell 2012, 22:180-193.

22. Vannucchi AM, Lasho TL, Guglielmelli P, Biamonte F, Pardanani A, Pereira A, Finke C, Score J, Gangat N, Mannarelli C, et al: Mutations and prognosis in primary myelofibrosis. Leukemia 2013, 27:1861-1869.

doi:10.1186/1756-8722-6-68

Cite this article as: Ferrer-Marín et al:: Leukemic transformation driven

by an ASXL1 mutation after a JAK2V617F-positive primary myelofibrosis: clonal evolution and hierarchy revealed by next-generation sequencing. Journal of Hematology \& Oncology 2013 6:68.

\section{Submit your next manuscript to BioMed Central and take full advantage of:}

- Convenient online submission

- Thorough peer review

- No space constraints or color figure charges

- Immediate publication on acceptance

- Inclusion in PubMed, CAS, Scopus and Google Scholar

- Research which is freely available for redistribution 